\title{
IX Congreso de historiadores de la minería latinoamericana
}

\author{
Carmen Salazar-Soler
}

\section{OpenEdition}

Journals

Edición electrónica

URL: http://journals.openedition.org/bifea/4001

DOI: 10.4000/bifea.400

ISSN: 2076-5827

Editor

Institut Français d'Études Andines

Edición impresa

Fecha de publicación: 1 agosto 2007

Paginación: 310-311

ISSN: 0303-7495

\section{Referencia electrónica}

Carmen Salazar-Soler, « IX Congreso de historiadores de la minería latinoamericana », Bulletin de I'Institut français d'études andines [En línea], 36 (2) | 2007, Publicado el 01 febrero 2008, consultado el 02 diciembre 2020. URL : http://journals.openedition.org/bifea/4001 ; DOI : https://doi.org/10.4000/ bifea.4001

\section{(c) $($ ) $\odot$}

Les contenus du Bulletin de l'Institut français d'études andines sont mis à disposition selon les termes de la licence Creative Commons Attribution - Pas d'Utilisation Commerciale - Pas de Modification 4.0 International. 


\section{CONGRESO DE HISTORIADORES DE LA MINERÍA LATINOAMERICANA}

Sucre, Potosí, 4-8 de abril de 2007

En el mes de abril del presente año se llevó a cabo en la ciudad de Sucre (Bolivia) el IX Congreso de Historiadores de la Minería Latinoamericana, organizado por la Coordinadora de Historia, el Archivo y las Bibliotecas Nacionales de Bolivia. Este congreso forma parte de un ciclo de reuniones que se organizan cada dos años con la finalidad de discutir las investigaciones relacionadas a la minería hispanoamericana. Como suele ocurrir en este ciclo de reuniones, el evento congregó a especialistas no solo del área andina sino también a historiadores mexicanos y franceses preocupados por la minería latinoamericana.

El congreso estuvo dividido en cinco mesas. La primera se dedicó a los descubrimientos de minas en la América española y fue coordinada por Pablo Quisbert de la Universidad Mayor de San Andrés. En dicha mesa, dos ponencias estuvieron enfocadas en Potosí. En una de ellas se presentaron los nuevos hallazgos arqueológicos en este histórico yacimiento y en la otra se abordó el tema del Cerro Rico y los descubrimientos de minas en Charcas durante el siglo XVI. Una tercera ponencia trató sobre el descubrimiento de las primeras minas de oro y plata en la Nueva España entre los años 1520 y 1532. Por último, se presentó una aproximación arqueológica al desarrollo minero en La Carolina (San Luis, Argentina) a fines del siglo XVIII. La discusión hizo resaltar la importancia del intercambio de ideas entre historiadores y arqueólogos para las investigaciones de la minería colonial.

La segunda mesa reunió estudios sobre las Casas de Moneda en Hispanoamérica. Una primera ponencia trató el interesante tema de la salud, enfermedad y previsión en la Real Casa de Moneda de México. La segunda ponencia abordó otro aspecto de la investigación sobre estas Casas y trató de las monedas y la Ceca de Lima en el siglo XVI.

La tercera mesa estuvo consagrada al tema del saber, ciencia y técnica en la minería latinoamericana y fue coordinada por la Dra. Carmen Salazar-Soler, investigadora del CNRS de Francia, quien en una ponencia introductoria destacó la importancia de contar por primera vez en este ciclo de reuniones, una mesa sobre ciencias y técnicas; y abogó por un estudio de la circulación del saber y de los conocimientos en la minería americana desde una perspectiva comparativa. Se presentaron tres ponencias, la primera de las cuales trató el tema de los inventos en la minería novohispana en el siglo XVI: se mostró el aporte de cada una de estas invenciones y se presentaron los planos y dibujos de uno de los inventos. En la segunda intervención se abordó el estudio de los sistemas de procesamiento de mineral de baja ley en el Sur de Chichas (Bolivia). La tercera exposición estuvo dedicada al saber técnico y saber esotérico entre los pirquineros del valle de Yocavil (noroeste argentino). Una nutrida discusión siguió a estas ponencias, donde destacaron los temas referidos a la relación entre el saber nativo y el saber europeo u occidental, el aporte de las innovaciones técnicas americanas a la minería occidental y la circulación entre varios continentes de ideas y personajes relacionados a la minería.

La cuarta mesa tuvo como tema general la minería colonial y estuvo coordinada por la Dra. Eugenia Bridikhina de la Carrera de Historia de la Universidad Mayor de San Andrés. Esta mesa contó con varias ponencias dedicadas a la minería novohispana; dos de ellas abordaron el estudio de los Reales de minas de Zacatecas durante el siglo XVIII y una tercera se ocupó de los delitos en las minas en la Real Casa de Moneda de México. En esta mesa se presentaron también tres ponencias sobre las minas de Oruro; la primera de ellas trató el tema de la minería en Oruro en la segunda mitad del siglo XVIII, la segunda se centró más bien en la minería orureña en la transición entre la Colonia y la República, y por último la tercera abordó el tema de la ciudad de Oruro y el inicio de la modernidad entre finales del siglo XIX e inicios del XX. Finalmente, se presentó una ponencia sobre los esclavos negros en el Potosí colonial.

La quinta mesa estuvo consagrada al tema «Sociedad y trabajadores en torno a la minería en los siglos XIX y XX» y estuvo a cargo de la Maestra Magdalena Cajías de la Carrera de Historia de la Universidad Mayor de San Andrés. Dos ponencias trataron de los problemas sociales en 
la región de Iquique: una primera se centró sobre el caso de la Mancomunal de los obreros de Iquique entre 1900 y 1909 y la segunda examinó la presencia boliviana en la masacre de Iquique de 1907. La historia colectiva de las mujeres mineras bolivianas ocupó la atención de una de las presentaciones. Al final, una de las exposiciones abordó problemas de historia contemporánea al tratar los impactos humanos de la globalización en las empresas mineras a través del estudio de caso de la compañía minera Autlán y sus trayectorias familiares en Hidalgo entre 1969 y el 2006.

Además de las ponencias mencionadas, al final de cada tarde hubo tres conferencias magistrales a cargo de distinguidos especialistas. La primera de ellas estuvo a cargo de la Dra. Ana María Presta quien expuso sobre «Potosí colonial y la minería en la historiografía argentina: el espacio de los maestros». La Licenciada Marcela Lynch, Directora del Archivo y Biblioteca Nacionales de Bolivia, brindó una conferencia sobre las «Fuentes documentales para la minería en el Archivo Nacional de Bolivia». La tercera conferencia magistral fue presentada por el Licenciado Luis Oporto, director de la Biblioteca y Archivo Histórico del Honorable Congreso Nacional de la República de Bolivia, quien trató el tema «Fuentes documentales para el estudio de la minería en Bolivia».

La presentación del excelente video documental de Magdalena Cajías, «Huanuni de pie a pesar de todo», cerró con broche de oro y de manera emotiva el IX Congreso de Historiadores de la Minería Latinoamericana. 